\title{
Investigation of the relationships between mechanical properties and microstructure in a $\mathrm{Fe}-9 \% \mathrm{Cr}$ ODS steel
}

\author{
Benjamin Hary ${ }^{1 *}$, Thomas Guilbert ${ }^{1}$, Pierre Wident ${ }^{1}$, Thierry Baudin ${ }^{2}$, Roland Logé $e^{3}$, and Yann de Carlan ${ }^{1}$ \\ ${ }^{1}$ Service de Recherches Métallurgiques Appliquées, CEA Saclay, 91191 Gif-sur-Yvette Cedex, France \\ 2 Institut de Chimie Moléculaire et des Matériaux d'Orsay, UMR CNRS 8182, SP2M, Université Paris-Sud, 91405 Orsay Cedex, \\ France \\ ${ }^{3}$ Laboratoire de Métallurgie Thermomécanique, École Polytechnique Fédérale de Lausanne, rue de la Maladière, 71b, CP 526, \\ CH-2002, Neuchâtel, Switzerland
}

Received: 30 April 2015 / Received in final form: 7 October 2015 / Accepted: 12 January 2016

Published online: 23 Febraury 2016

\begin{abstract}
Ferritic-martensitic Oxide Dispersion Strengthened (ODS) steels are potential materials for fuel pin cladding in Sodium Fast Reactor (SFR) and their optimisation is essential for future industrial applications. In this paper, a feasibility study concerning the generation of tensile specimens using a quenching dilatometer is presented. The ODS steel investigated contains $9 \% \mathrm{Cr}$ and exhibits a phase transformation between ferrite and austenite around $870{ }^{\circ} \mathrm{C}$. The purpose was to generate different microstructures and to evaluate their tensile properties. Specimens were machined from a cladding tube and underwent controlled heat treatments inside the dilatometer. The microstructures were observed using Electron Backscatter Diffraction (EBSD) and tensile tests were performed at room temperature and at $650{ }^{\circ} \mathrm{C}$. Results show that a tempered martensitic structure is the optimum state for tensile loading at room temperature. At $650{ }^{\circ} \mathrm{C}$, the strengthening mechanisms that are involved differ and the microstructures exhibit more similar yield strengths. It also appeared that decarburisation during heat treatment in the dilatometer induces a decrease in the mechanical properties and heterogeneities in the dual-phase microstructure. This has been addressed by proposing a treatment with a much shorter time in the austenitic domain. Thereafter, the relaxation of macroscopic residual stresses inside the tube during the heat treatment was evaluated. They appear to decrease linearly with increasing temperature and the phase transformation has a limited effect on the relaxation.
\end{abstract}

\section{Introduction}

Research works performed during recent years have revealed that ODS (Oxide Dispersion Strengthened) steels are promising materials for fuel pin cladding in Sodium Fast Reactors $[1,2]$. It appears that the bcc ferritic-martensitic lattice allows for a high resistance to irradiation swelling up to a dose of around 150 displacements per atom (dpa) and nano-oxides significantly improve creep and tensile properties at high temperature $\left(650^{\circ} \mathrm{C}\right)$ by blocking the dislocations motion.

ODS steels are created by powder metallurgy and mechanical alloying [3] in order to obtain a fine homogeneous dispersion of the nano-oxides within the matrix. Afterwards, the powder is compacted in a soft steel can and hot extruded. The soft steel is removed from the raw bar obtained and only the ODS steel remains. Then, the bar is

\footnotetext{
* e-mail: benjamin.hary@cea.fr
}

cold-worked into the shape of a cladding tube by several passes of rolling. This manufacturing process tends to create a crystallographic $(\alpha$ fiber $<110>$ ) and a morphologic texture into the material. These passes also induce important residual stresses that can be limited or annealed by intermediate heat treatments that decrease hardness and prevent the tube from being damaged.

A martensitic ODS tube with $9 \% \mathrm{Cr}$ has been studied. With a heating rate of $5{ }^{\circ} \mathrm{C} / \mathrm{s}$, this grade exhibits a phase transformation from ferrite to austenite between $870{ }^{\circ} \mathrm{C}$ $\left(\mathrm{A}_{\mathrm{s}}\right)$ and $960^{\circ} \mathrm{C}\left(\mathrm{A}_{\mathrm{f}}\right)$ that enables a total recovery of the microstructure and facilitates cold-working of the tube $[4,5]$, since the material does not recrystallise in the ferritic state [6]. Moreover, it is possible to obtain different microstructures from ferrite to martensite by applying various cooling rates from the austenitic domain. This investigation focused on an analytic method to treat tensile specimens in order to generate different microstructures. It employed a dilatometer to precisely control thermal cycles and to measure the dimensional variations of the sample. 
Table 1. Chemical composition of the ODS steel grade K30-M1.

\begin{tabular}{cccccc}
\hline & $\mathrm{Cr}$ & $\mathrm{W}$ & $\mathrm{Ti}$ & $\mathrm{Y}$ & $\mathrm{Ni}$ \\
wt.\% & 9.08 & 1.05 & 0.2 & 0.19 & 0.2 \\
& $\mathrm{Mn}$ & $\mathrm{Si}$ & $\mathrm{C}$ & $\mathrm{O}$ & $\mathrm{N}$ \\
wt.\% & 0.29 & 0.23 & 0.109 & 0.12 & 0.022 \\
\hline
\end{tabular}

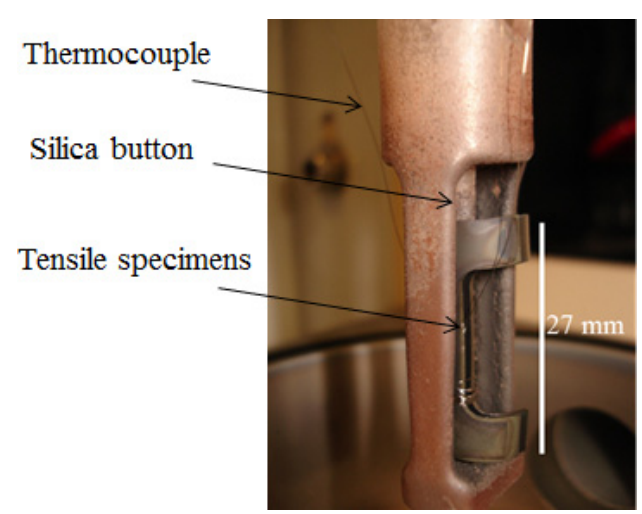

Fig. 1. Experimental device.

The aim was to perform different final heat treatments, assess the mechanical properties and determine the best compromise between ductility and tensile strength. Another purpose of the study was to understand the macroscopic residual stresses relaxation (1st order stresses) inside the cladding tube during the heat treatments.

\section{Microstructural characterisation}

\subsection{Generation of microstructures for mechanical assessments}

The chemical composition of the ODS steel tube investigated is presented in Table 1. The raw bar was extruded at $1100{ }^{\circ} \mathrm{C}$ and a tempering treatment was performed at $1050{ }^{\circ} \mathrm{C}$ for $30 \mathrm{~min}$. Then, the soft steel was removed by chemical dissolution. In order to obtain the cladding tube, the bar was cold-rolled in the ferritic state with intermediate heat treatments in the austenitic domain. After each intermediate heat treatment, the tube was cooled at a slow rate $\left(0.05^{\circ} \mathrm{C} / \mathrm{s}\right)$. At the end of the manufacturing process, the cladding tube exhibits a coldrolled ferritic microstructure. In the following, this tube will be named K30-M1.

Tensile specimens $\left(27 \times 2 \times 0.5 \mathrm{~mm}^{3}\right)$ were machined from the ferritic tube in the axial direction before undergoing a controlled heat treatment in a dilatometer under helium atmosphere. This high-speed Adamel-Lhomargy DT1000 dilatometer, retrofitted by AET Technologies, provides access to a broad range of cooling rates, from $0.1^{\circ} \mathrm{C} / \mathrm{s}$ to $100{ }^{\circ} \mathrm{C} / \mathrm{s}$ using a cryogenic system with liquid nitrogen. Two thermocouples (Fig. 1) allow measurement of the real specimen temperature on the specimens throughout the experiment. In order to prevent welding defects on the

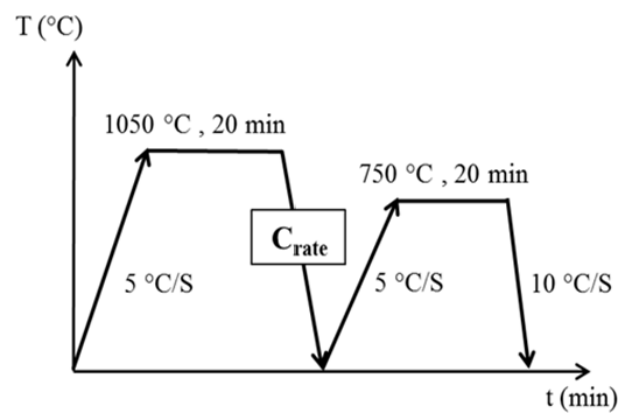

Fig. 2. Applied heat treatment for microstructure generation.

specimen form affecting the results of the mechanical test, thermocouples are welded onto a second specimen which is not submitted to this test. A sensor motion (silica probe) is used to measure the dimensional variation of the specimen and to identify the allotropic phase transformations during the heat treatment. The applied heat treatment presented in Figure 2 was an austenitisation plateau at $1050{ }^{\circ} \mathrm{C}$ for 20 minutes, followed by a cooling where the rate is carefully chosen. Then, a tempering treatment was performed at $750{ }^{\circ} \mathrm{C}$ for 20 minutes to allow carbide precipitation inside the martensite. Three different cooling rates $\left(\mathrm{C}_{\text {rate }}\right)$ were chosen from the CCT diagram [7] in order to obtain the following microstructures: tempered martensite $\left(10^{\circ} \mathrm{C} / \mathrm{s}\right)$, dual-phase $50 \%$ martensite- $50 \%$ ferrite $\left(2{ }^{\circ} \mathrm{C} / \mathrm{s}\right)$ and ferrite $\left(0.1^{\circ} \mathrm{C} / \mathrm{s}\right)$.

Once the specimens were treated, tensile tests were performed in the longitudinal direction at room temperature and at $650{ }^{\circ} \mathrm{C}$ with a strain rate of $7 \times 10^{-4} / \mathrm{s}$. Observation of the fracture surfaces has enabled identification of the rupture mechanisms. The same treatments were applied to cylinders cut from the tube in order to characterise each microstructure using an EBSD (Electron Backscatter Diffraction) system installed on a FEG-SEM. The samples were prepared by vibratory auto-polishing using non-crystalline colloidal silica for several hours. Analyses were made in the rolling plane, along the axial direction of the tube.

\subsection{Results}

According to the dilation curves presented in Figures $3 \mathrm{a}$, 4a and $5 \mathrm{a}$, the microstructures have been generated as expected. The expansion during heating is the same for the three samples, with an austenitisation around $870{ }^{\circ} \mathrm{C}$ $\left(A_{\mathrm{S}}\right)$. On the other hand, significant changes can be 

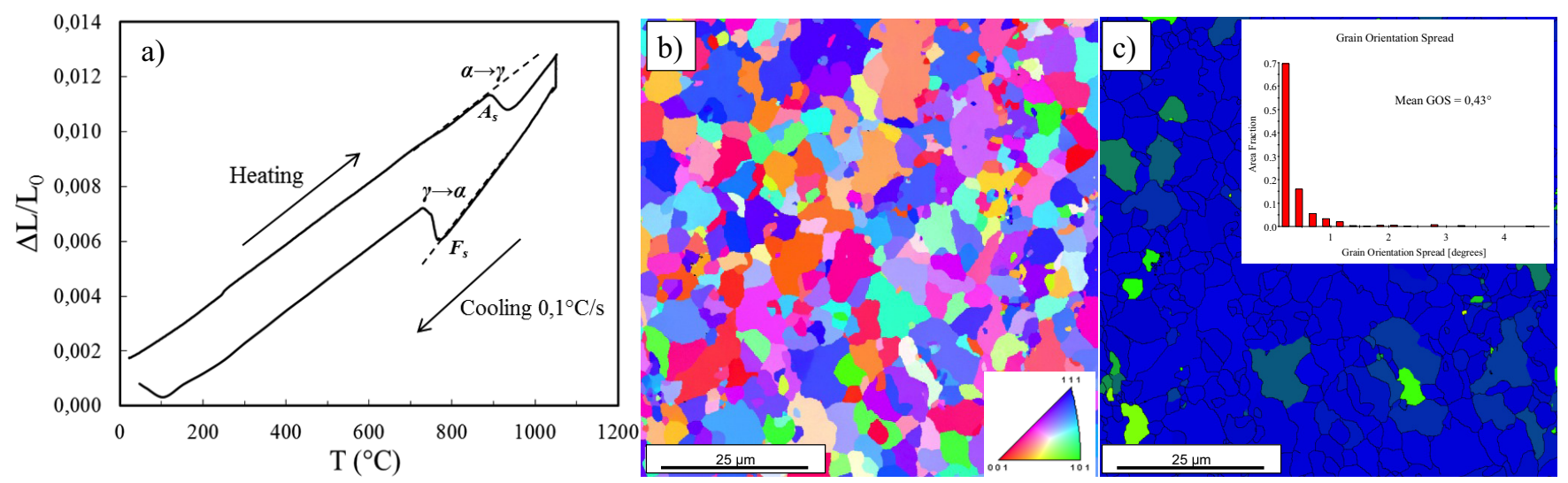

Fig. 3. (a) Dilation curve, (b) grain orientation map showing normal of crystalline planes parallel to the rolling direction $\left(75 \times 75 \mu \mathrm{m}^{2}\right.$, scanning step: $0.1 \mu \mathrm{m}$, correctly indexed pixels: 100\%), and (c) GOS map for the ferritic microstructure.
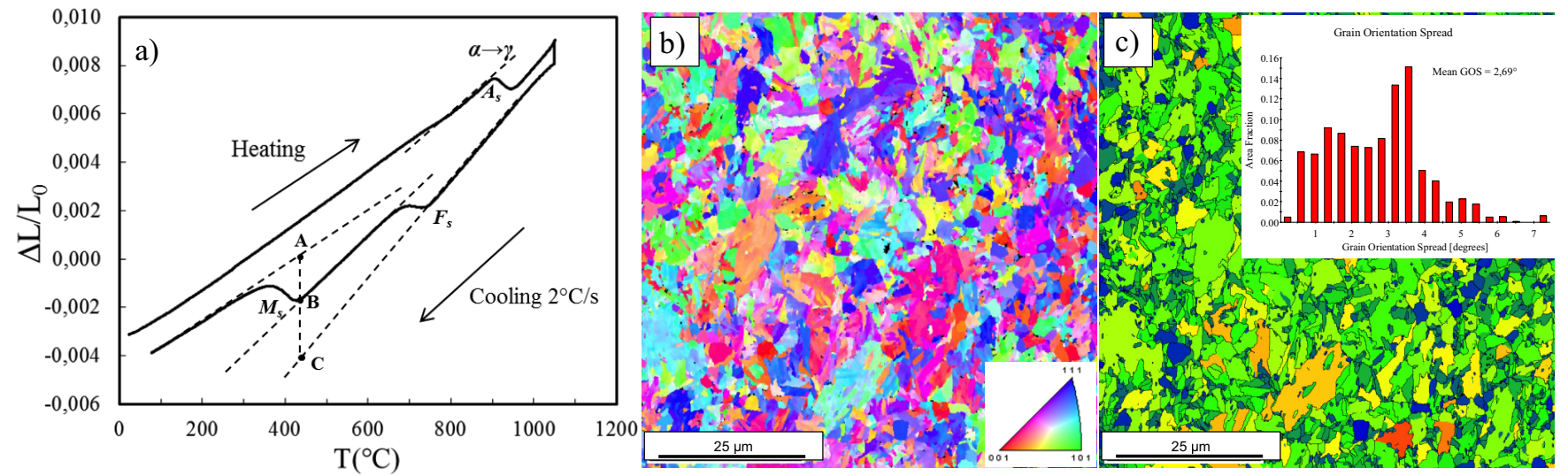

Fig. 4. (a) Dilation curve, (b) grain orientation map showing normal of crystalline planes parallel to the rolling direction $\left(75 \times 75 \mu \mathrm{m}^{2}\right.$, scanning step: $0.1 \mu \mathrm{m}$, correctly indexed pixels: $99.4 \%$ ) and (c) GOS map for the dual-phase microstructure.
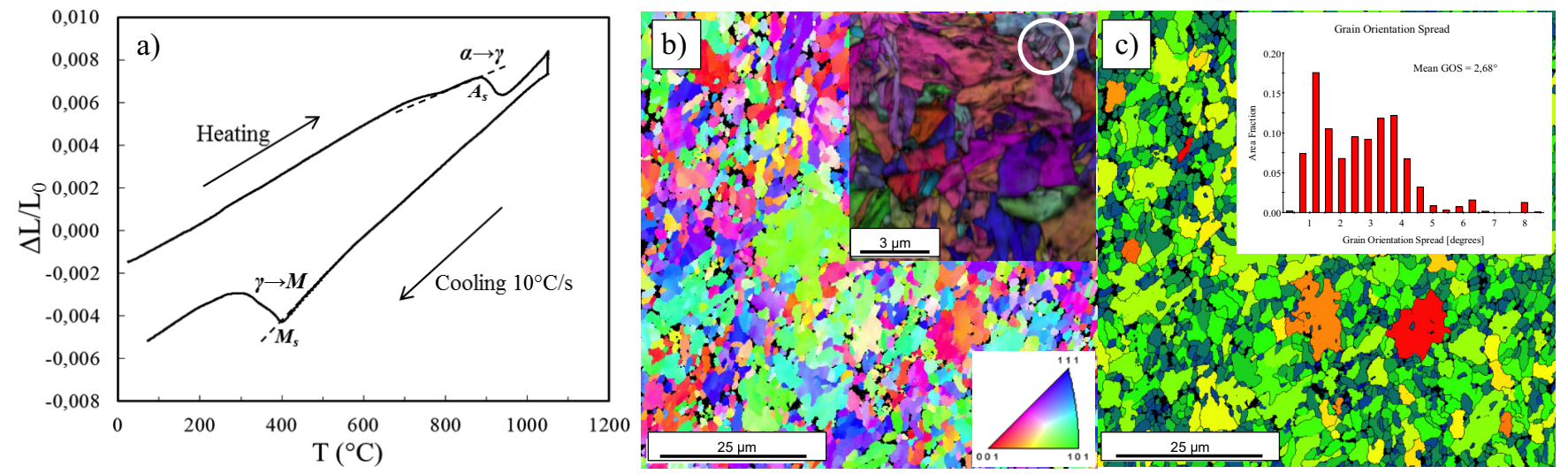

Fig. 5. (a) Dilation curve, (b) grain orientation map showing normal of crystalline planes parallel to the rolling direction $\left(75 \times 75 \mu \mathrm{m}^{2}\right.$, scanning step: $0.1 \mu \mathrm{m}$, correctly indexed pixels: $94 \%$ ), and (c) GOS map for the martensitic microstructure.

observed during cooling. In Figure 3a, only the ferritic transformation $\left(\mathrm{F}_{\mathrm{s}}\right)$ around $780{ }^{\circ} \mathrm{C}$ is apparent. Figure $4 \mathrm{a}$ shows that both ferritic and martensitic transformations have occurred, and their proportion can be graphically estimated by comparing the $\mathrm{AB}$ and $\mathrm{BC}$ segments. The uncertainty in the fraction phases is about 10\% using this method. Here, the two segments are equivalent and thus the fractions of phases: about $50 \%$ ferrite and $50 \%$ martensite.
Then, Figure 5a shows that only martensite is created from temperature $\mathrm{M}_{\mathrm{s}}$. EBSD data were treated with the OIM Analysis software, developed by the EDAX society. The cleanup procedure used to analyse the data was a Grain Dilation (one iteration, minimum grain size $=5$, grain tolerance angle $=5$ ) followed by a Grain CI Standardisation (same parameters). Then, only the points with a confidence index higher than 0.1 were taken into account. 


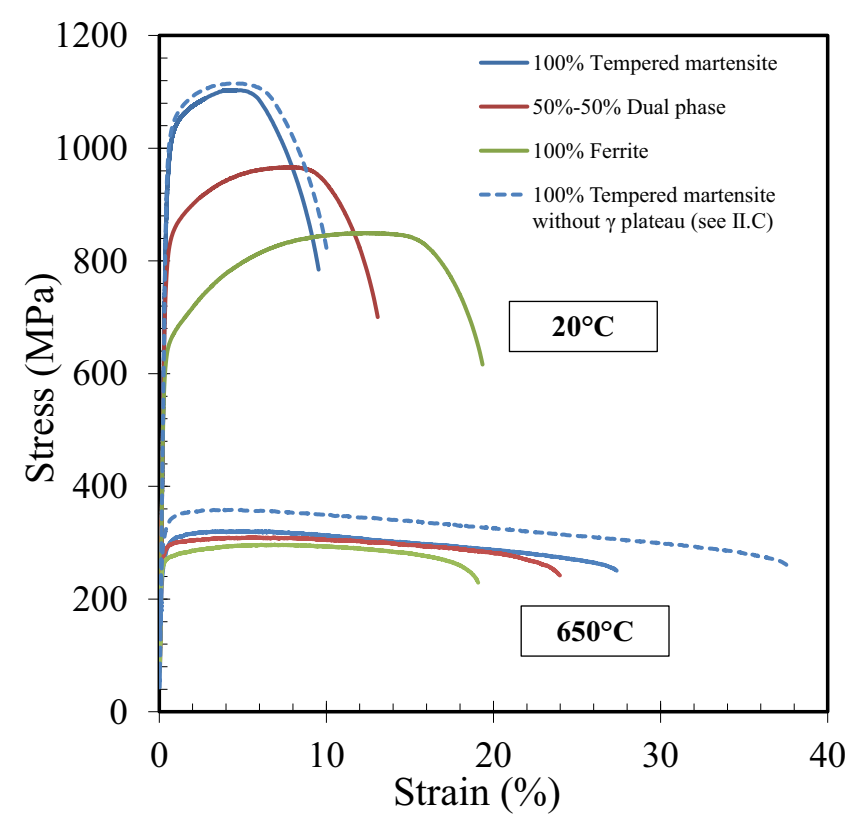

Fig. 6. Tensile properties of the microstructures created using the dilatometer.

All of the grain orientation maps show neither crystallographic texture nor morphologic texture, which confirmed the reset effect of the phase transformation during the heat treatment. Figure $3 \mathrm{~b}$ shows a recrystallised ferritic structure composed of equiaxed grains with a mean size of $5.5 \mu \mathrm{m}$ whereas the martensitic structure (Fig. 5b) is composed of smaller grains with a mean size of $3.6 \mu \mathrm{m}$. The scan performed at a smaller scale with an analysis step of $10 \mathrm{~nm}$ enables observation of substructures in the martensite (see the white circle) which could be identified as laths, blocks or packets. Figure $4 \mathrm{~b}$ shows the microstructure of the dual-phase sample. The fine grains make the identification of ferrite and martensite difficult, and an alternative method was used to distinguish the two phases: the Grain Orientation Spread (GOS). This method uses the EBSD dataset to estimate the intragranular misorientation of each grain in the microstructure [8]. The GOS distribution was calculated for the three microstructures. The misorientation inside ferritic grains is very low (mean GOS $0.4^{\circ}$ ) compared to the one in martensitic grains (mean GOS $2.7^{\circ}$ ). This can be attributed to the fact that just after the cooling, the dislocation density is higher in the martensite than in the ferrite. Thus, martensite and ferrite grains can be distinguished on the basis of their GOS value.

Considering this, the dual-phase microstructure seems to contain much more martensite than ferrite, which is a surprising result according to the dilation curve. This is discussed in the following sections.

From Figure 6, tensile tests performed at room temperature show a significant strain hardening. The yield strength increases with increasing martensitic content, and the maximum uniform elongation decreases.

The fracture surfaces on the three microstructures showed numerous dimples (Figs. $7 \mathrm{a}$ and $7 \mathrm{~b}$ ), characteristic of a ductile behaviour. One can point out a strong relationship between the microstructure and the tensile
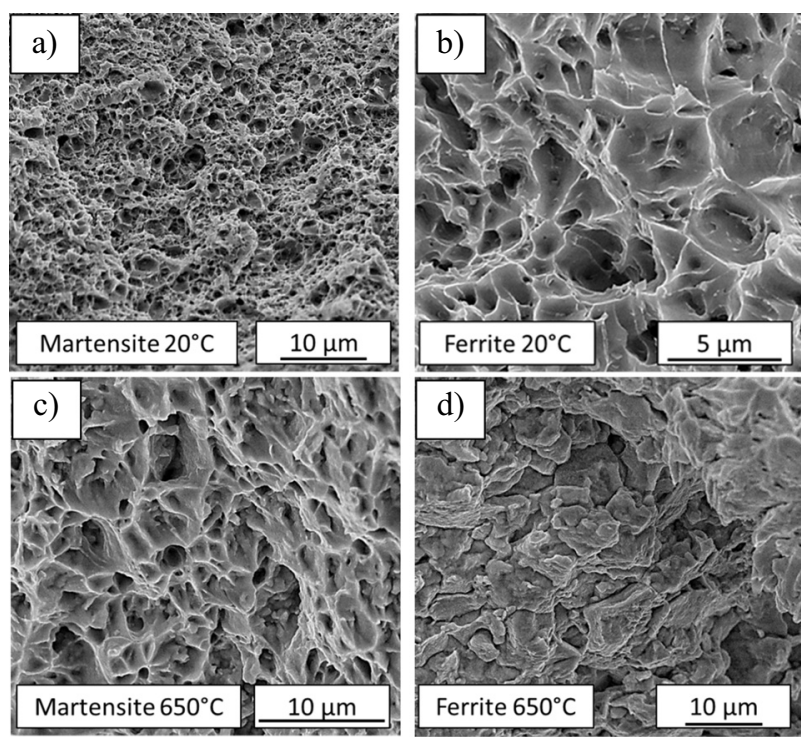

Fig. 7. Fracture surfaces of tensile specimens.

properties at this temperature. The results obtained at high temperature are quite different: On the one hand, the dependence of the yield strength on the microstructure is highly reduced. In addition, the strain hardening is much less significant at this temperature for the three microstructures. On the other hand, the fracture strain of the annealed martensite increases significantly from $10 \%$ to almost $30 \%$, whereas it remains the same as at room temperature for the ferrite, around 20\%. The maximum uniform elongation remains higher for the ferrite but is divided by two $(12 \%$ at $20^{\circ} \mathrm{C}$ and $6.7 \%$ at $650{ }^{\circ} \mathrm{C}$ ), whereas it remains almost the same for martensite, around $4.5 \%$. Analysis of fracture surfaces shows dimpled features in the martensite (Fig. 7c) and in the dual-phase, but some intergranular decohesion areas in the ferrite (Fig. 7d). This may be responsible for the less ductile behaviour of ferrite at $650{ }^{\circ} \mathrm{C}$. In the literature [9], intergranular decohesion mechanisms have already been observed in ferritic ODS $(14 \% \mathrm{Cr})$ steels above $600{ }^{\circ} \mathrm{C}$ caused by cavities lining up along the grain boundaries.

\subsection{Discussion}

Based on these mechanical tests, the martensitic structure seems to be the optimum state to withstand the tensile loading at room temperature. In fact, it shows the highest strength and a ductile behaviour. Several contributions can be identified to explain this difference. According to the HallPetch effect, the presence of the finer grains in martensite induces a higher yield strength as compared to ferrite. In addition, the higher dislocation density created by the displacive transformation is also known to reinforce the material. Finally, the precipitation of carbides in $9 \% \mathrm{Cr}$ ODS steel can vary significantly between the microstructures, as observed by Klimiankou et al. [10]. In ferrite, they tend to nucleate at the grain boundaries and are essentially coarse $\mathrm{M}_{23} \mathrm{C}_{6}(\mathrm{M}=\mathrm{Fe}, \mathrm{Cr}, \mathrm{W})$ or TiC carbides. On the other hand, for a tempered martensitic structure, the carbides are likely to nucleate more homogeneously in the microstructure. 


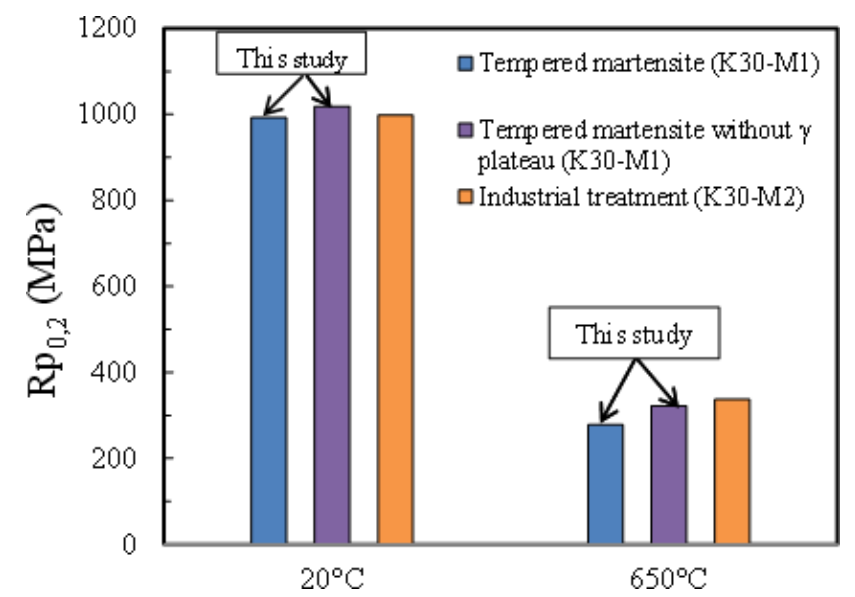

Fig. 8. Yield strength comparison at $20^{\circ} \mathrm{C}$ and $650^{\circ} \mathrm{C}$ of different $9 \% \mathrm{Cr}$ ODS steel cladding tubes investigated at CEA.

This can be attributed to a smaller grain size and a more significant number of interfaces. Considering an Orowan strengthening mechanism, the lower the distance between particles, the higher the strengthening effect will be. These hardening mechanisms could explain the higher mechanical resistance of martensite at room temperature.

At $650{ }^{\circ} \mathrm{C}$, the relationships between the mechanical properties and the microstrutures are more difficult to explain. The yield strength of martensite is almost the same as that of ferrite. This weak variation of the yield strength with tensile loading at high temperature between different 9\% Cr ODS steel microstructures has already been observed [11]. It suggests that the strengthening mechanisms that make martensite much more resistant than ferrite at room temperature are not the same at $650{ }^{\circ} \mathrm{C}$. In different studies [12-14], the presence of residual ferrite was found. This phase did not undergo the austenitisation and TEM analysis showed that it contains a higher density and a finer diameter of nano-particles than martensite. It leads to a more important pinning of the dislocations considering an Orowan mechanism, which would become predominant at high temperature, and so a hardening of the ferrite. However, there is no presence of residual ferrite in the present work. The samples seemed to undergo a full austenitisation according to the recrystallised ferritic structure in Figures $3 \mathrm{~b}$ and $3 \mathrm{c}$. This may be due to a lower content of alphagen alloying elements in K30-M1, increasing the driving force for austenitisation. Consequently, the most plausible explanation for the similar yield strength at $650^{\circ} \mathrm{C}$ would be a very low contribution of dislocations and Hall-Petch effect in the strengthening mechanisms.

In order to evaluate the efficiency of controlled treatments in the dilatometer, the tensile properties of the martensitic sample were compared to those of another ODS $9 \% \mathrm{Cr}$ cladding tube (named K30-M2) studied at CEA $[15,16]$, created from the same powder, and presenting the same chemical composition. The cladding tube of this grade was treated in a classical (industrial) furnace at $1050{ }^{\circ} \mathrm{C}$ for $30 \mathrm{~min}$ and cooled at $70^{\circ} \mathrm{C} / \mathrm{min}$. Then, a softening treatment at $750^{\circ} \mathrm{C}$ for one hour was performed. Tensile specimens were machined afterwards. This tube will be called "industrial grade" in the following. The cooling rate is a parameter of the

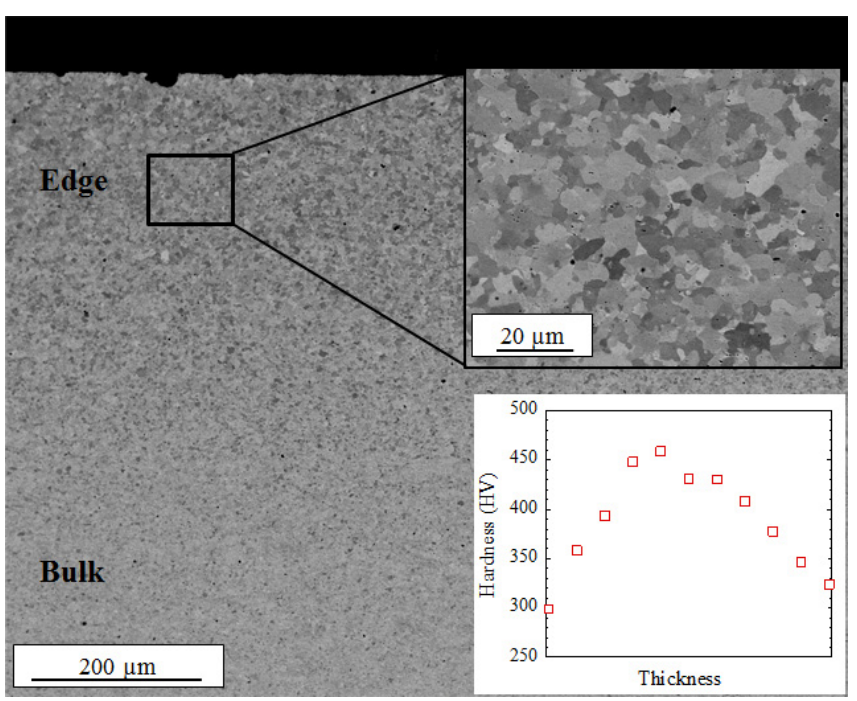

Fig. 9. SEM image of the microstructure of the dual-phase sample, from the edge of the tube to the core and hardness distribution across the thickness of the tube.

furnace and was not measured directly on the tube during the treatment. The atmosphere in the furnace is a primary vacuum. The microstructure of the industrial grade was observed and essentially showed laths of martensite. One should note that the industrial grade has undergone a lower cooling rate under a less controlled atmosphere than the K30M1 martensitic specimen heat treated in the dilatometer. Despite these considerations, Figure 8 shows that the yield strength of tempered martensite $\mathrm{K} 30-\mathrm{M} 1$ (blue) at $650{ }^{\circ} \mathrm{C}$ is about $60 \mathrm{MPa}$ lower than that of the industrial grade (orange). The experimental uncertainty on the yield strength was considered to be $10 \mathrm{MPa}$.

To explain these results, a decarburisation inside the dilatometer during the austenitisation seems to be the most probable hypothesis. In fact, observations on the dualphase cylindrical sample using SEM with the backscattering electron detector in Figure 9 showed only large grains on the edge of the sample. It is known that low carbon content promotes growth of ferrite [13] and thus increases the quench critical rates, which determine the formation domain of the different microstructures. To support this hypothesis, micro-hardness measurements (load $100 \mathrm{~g}$ ) were performed across the thickness of the tube. The maximum hardness $(450 \mathrm{HV})$ is located at the half-thickness, whereas the minimum $(300 \mathrm{HV})$ is located at the edges. Thus, one can suggest that during cooling, ferrite nucleated at the edge where the carbon content was low and martensite appeared in the bulk of the sample.

This is in agreement with the GOS map in Figure 4c where most of the grains showed a high stored energy and are probably grains of martensite (EBSD analysis was performed in the bulk). In order to have a more accurate idea of the decarburisation, carbon content after the heat treatment could be measured using EPMA (Electron MicroProbe Analysis) or a melting method (LECO) and be compared with the initial content in the tube $(0.109 \%)$.

The decarburisation thickness can be estimated by calculating the diffusion length of carbon into the material. 

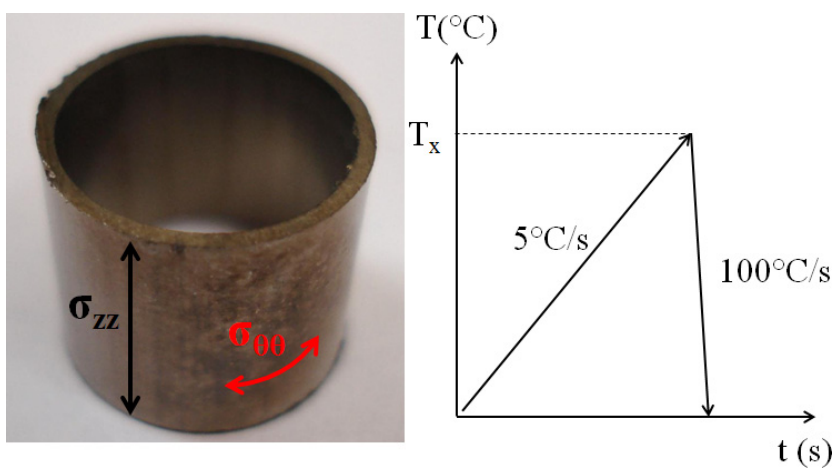

Fig. 10. Component of stress tensor inside the tube and applied heat treatment.

As a first approximation, the diffusion coefficient of carbon within pure iron is used. According to Bakker et al. [17], it is estimated as $3.8 \times 10^{-11} \mathrm{~m}^{2} / \mathrm{s}$ at $1050^{\circ} \mathrm{C}$. Considering this approximation and a diffusion time of 20 minutes, one obtains a diffusion length around $300 \mu \mathrm{m}$. Knowing that the tensile specimens are only $500 \mu \mathrm{m}$ thick, a significant amount of carbon is likely to escape from the samples. To prevent this decarburisation, a new heat treatment without austenitisation plateau was performed into the dilatometer to get a tempered martensitic microstructure. The increased carbon content in this sample as compared to that with the initial treatment has been confirmed by looking at the two martensitic start temperatures $\left(\mathrm{M}_{\mathrm{s}}\right)$. On the dilation curves, it can be seen that the austenitization plateau of the initial treatment induces a shift of $\mathrm{M}_{\mathrm{s}}$ around $30{ }^{\circ} \mathrm{C}$ towards higher temperatures to $400{ }^{\circ} \mathrm{C}$ (Fig. 4a). The Andrews relation [18] gives:

$$
\begin{aligned}
M_{s}\left({ }^{\circ} \mathrm{C}\right)= & 539-423 \% \mathrm{C}-30.4 \% \mathrm{Mn}-17.7 \% \mathrm{Ni}- \\
& 12.1 \% \mathrm{Cr}-11 \% \mathrm{Si}-7 \% \mathrm{Mo} .
\end{aligned}
$$

Using this formula and the chemical composition of the material, one finds a carbon loss of approximately $70 \%$ due to the austenitisation for 20 minutes at $1050{ }^{\circ} \mathrm{C}$. Therefore, it can be noted in Figure 8 that the new treatment induces stronger mechanical properties for the tempered martensite (purple) than the initial one. The increase of the yield strength is $27 \mathrm{MPa}$ at room temperature and $44 \mathrm{MPa}$ at $650{ }^{\circ} \mathrm{C}$. This improvement of the mechanical properties between these two tempered martensitic samples shows that the precipitation of carbides has a significant reinforcement role within the material, particularly at high temperature. This is in agreement with a predominant role of the Orowan mechanism at $650^{\circ} \mathrm{C}$, as previously mentioned.

\section{Macroscopic residual stresses relaxation}

\subsection{Experimental procedure}

The dilatometer was used to evaluate the efficiency of simple heat treatments on the relaxation of first order residual stresses after cold-rolling. Both orthoradial $\left(\sigma_{\theta \theta}\right)$ and longitudinal $\left(\sigma_{\mathrm{zz}}\right)$ macroscopic residual stress have
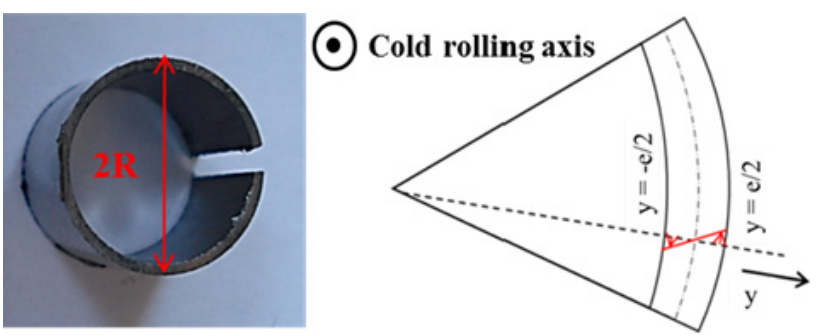

Fig. 11. Orthoradial stress measurement.

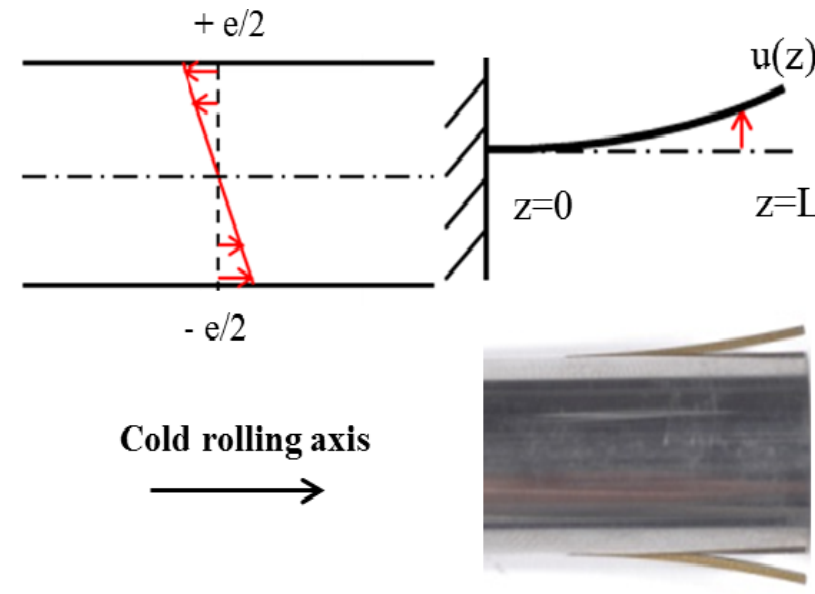

Fig. 12. Longitudinal stress measurement.

been sources of interest. The measurements were made with the calculation method proposed by Béchade et al. [19]. An elastic behaviour model was used. In the framework of this study, the hardening during cold-rolling was assumed to be isotropic (no kinematical hardening).

Moreover, the following hypotheses were considered: a transversal isotropic stress state and a linear gradient of the stresses in the thickness of the tube, as presented in Figures 11 and 12. To perform this experiment, $9 \mathrm{~mm}$ long cylinders were cut from the as-rolled tube and heated at different temperatures ( $T_{\mathrm{x}}$ on Fig. 10 ) between $400^{\circ} \mathrm{C}$ and $950{ }^{\circ} \mathrm{C}$. Then a very rapid quench $\left(100^{\circ} \mathrm{C} / \mathrm{s}\right)$ was applied to freeze the microstructure and thus the stress state. Residuals stresses were measured at room temperature. Samples were cut with an aluminum oxide grindstone. Deformations were measured with a micrometer (uncertainty of $10 \mu \mathrm{m}$ induces an uncertainty of $10 \mathrm{MPa}$ on the stress).

\subsubsection{Orthoradial stresses}

The orthoradial residual stresses were estimated by cutting the cylinder along the longitudinal direction. The measurement of the opening can give access to the maximal residual stress using the following formula [20]:

$$
\sigma_{\theta \theta}^{\max }=E \cdot \frac{e}{2} \cdot\left(\frac{1}{R_{0}}-\frac{1}{R}\right)
$$




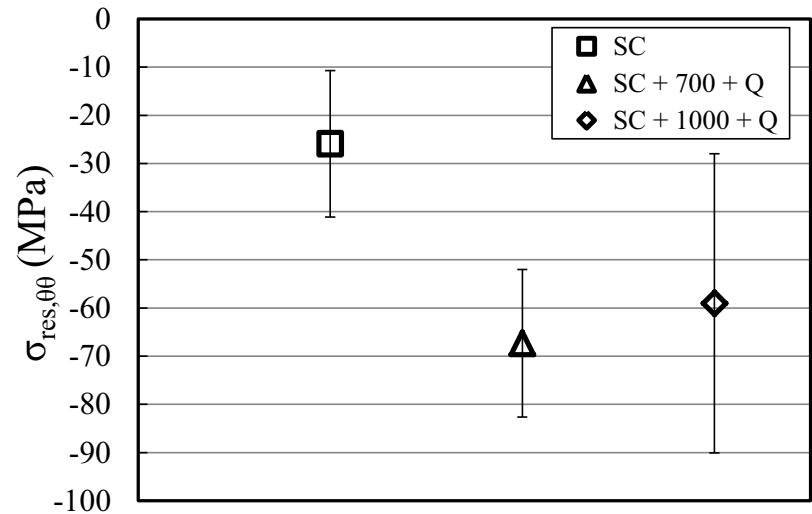

Fig. 13. Macroscopic residual stress evolution during the heat treatment.

where $E$ is the Young's Modulus of the steel (225 GPa), $e$ is the thickness of the tube, $R_{0}$ is the radius before cutting and $R$ is the radius after cutting.

\subsubsection{Longitudinal stresses}

Two stripes were diametrically cut along the cylinder. Measurement of the spire enables calculation of the maximal longitudinal residual stress $[4,10]$ :

$$
\sigma_{z z}^{\max }=-\frac{u(L) \cdot E}{L^{2}} e
$$

where $u(L)$ is the spire, $L$ is the length of the stripes and $e$ is the thickness of the tube.

\subsection{Results and discussion}

To discuss the results on a sound basis, the contribution of quenching to the orthoradial residual stresses was also studied (for experimental reasons, it was not possible to do this for the longitudinal stresses). Stresses were measured after three different heat treatments:

- Austenitisation + slow cooling at $0.1^{\circ} \mathrm{C} / \mathrm{s}(\mathrm{SC})$;

- Austenitisation + slow cooling + heating to $700{ }^{\circ} \mathrm{C}+$ quench at $100^{\circ} \mathrm{C} / \mathrm{s}(\mathrm{SC}+700+\mathrm{Q})$;

- Austenitisation + slow cooling + heating to $1000{ }^{\circ} \mathrm{C}+$ quench at $100^{\circ} \mathrm{C} / \mathrm{s}(\mathrm{SC}+1000+\mathrm{Q})$.

According to the literature [20], the first treatment should give a zero stress state, while the second and third treatments should give contributions of quenching from the ferritic domain and from the austenitic domain, respectively. From Figure 13, one can conclude that orthoradial stresses after slow cooling are negligible taking into account the uncertainty. The slight difference from zero may have been introduced by the cutting method. On the other hand, compressive stresses of about $60 \mathrm{MPa}$ are measured after quenching from $700{ }^{\circ} \mathrm{C}$ and $1000^{\circ} \mathrm{C}$. There does not appear to be a difference between quenching from $700{ }^{\circ} \mathrm{C}$ (ferritic domain) or from $1000{ }^{\circ} \mathrm{C}$ (austenitic domain), so the effect of martensitic transformation is

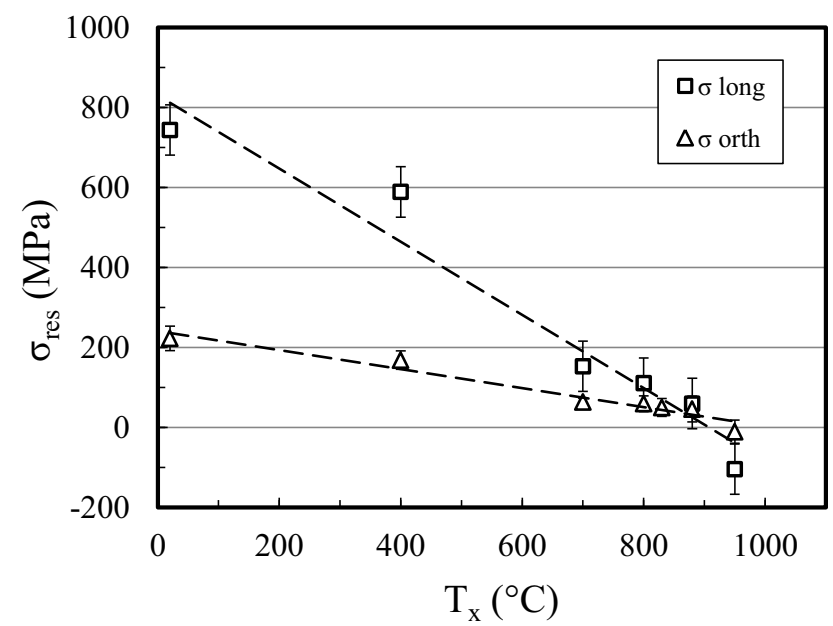

Fig. 14. Contribution of quenching on the orthoradial residual stresses.

negligible, at least for the first order stresses. These quenching stresses should be taken into account in the measures.

Figure 14 shows the macroscopic residual stresses measured at room temperature inside the tube after a heating at temperature $T_{\mathrm{x}}$. At room temperature, longitudinal stresses are much more significant than the orthoradial stresses and reach $750 \mathrm{MPa}$. With increasing temperature, both longitudinal and orthoradial stresses decrease linearly when the material is in the ferritic state. The macroscopic residual stresses are almost removed at the austenitisation start temperature $\left(\mathrm{A}_{\mathrm{s}}\right)$, around $880^{\circ} \mathrm{C}$. The slight compressive value for the treatment at $950^{\circ} \mathrm{C}$ can be attributed to quenching: once residual stresses due to cold-rolling are relaxed, only the contribution of quenching remains.

One can conclude that the phase transformation is not responsible for the relaxation of the first order residual stresses, which is an unexpected result. Indeed, one could have expected a plateau from room temperature to $\mathrm{A}_{\mathrm{s}}$ and then a sharp decrease of the residual stresses due to the phase transformation. To understand this phenomenon, further experiments using X-ray diffraction would be necessary to obtain the residual stresses tensor and identify the relaxation mechanisms. In fact, different hypotheses could be considered, such as small intragranular dislocation motions or rearrangements at grains boundaries. It would also be interesting to perform this analytic experiment on a ferritic ODS $14 \% \mathrm{Cr}$ steel, that does not present a phase transformation.

\section{Conclusion}

A quenched dilatometer was used to generate microstructures from ferrite to martensite in a $9 \% \mathrm{Cr}$ ODS steel cladding tube. Microstructures were observed and tensile tests were carried out at room temperature and at $650{ }^{\circ} \mathrm{C}$. The keys findings are as follows:

- EBSD data analyses have enabled us to distinguish martensite from ferrite according to the intragranular 
misorientation. Tensile tests have shown that the tempered martensitic microstructure is optimal for tensile loading at room temperature. At $650{ }^{\circ} \mathrm{C}$, the mechanisms governing the mechanical resistance are different. The yield strength of ferrite becomes almost equivalent to that of martensite, but its behaviour is less ductile. This could be due to a similar contribution of the Hall-Petch effect and dislocations in the microstructures; - an experimental artefact, decarburisation inside the dilatometer, led to weaker mechanical properties as compared to the industrial grade and heterogeneous microstructure in the dual-phase sample, with ferrite in the edges and martensite in the bulk. This decarburisation can be corrected by removing the austenitisation plateau from the heat treatment. It shows encouraging results for the tempered martensite, since one can achieve higher yield strength.

The macroscopic residual stress relaxation inside the tube during the heat treatment was measured. The investigation shows that it decreases linearly in the ferritic state with increasing temperature, and reaches a zero stress state at $950^{\circ} \mathrm{C}$. Thus, the relaxation mechanisms are not induced by the phase transformation. X-ray diffraction would be interesting to more completely understand this phenomenon.

The authors would like to thank Jean-Luc Flament for the realisation of the mechanical tests, Annick Bougault for her help in analysing the fracture surfaces and Patrick Bonnaillie for the SEM images.

\section{References}

1. Y. de Carlan, J.-L. Béchade, P. Dubuisson et al., CEA development of new ferritic ODS alloys for nuclear application, J. Nucl. Mater. 386-388, 430 (2009)

2. P. Dubuisson, Y. de Carlan, V. Garat, M. Blat, ODS Ferritic/ martensitic alloys for Sodium Fast Reactor fuel pin cladding, J. Nucl. Mater. 428, 6 (2012)

3. J.S. Benjamin, Dispersion strengthened superalloys by mechanical alloying, Metall. Trans. 1, 2943 (1970)

4. L. Toualbi, C. Cayron, P. Olier, R. Loge, Y. de Carlan, Relationships between mechanical behavior and microstructural evolutions in Fe 9Cr-ODS during the fabrication route of SFR cladding tubes, J. Nucl. Mater. 42, 410 (2013)

5. L. Toualbi, C. Cayron, P. Olier et al., Assessment of a new fabrication route for $\mathrm{Fe}-9 \mathrm{Cr}-1 \mathrm{~W}$ ODS cladding tubes, J. Nucl. Mater. 428, 47 (2012)

6. H.R.Z. Sandim, R.A. Renzetti, A.F. Padilha, D. Raabe, M. Klimenkov, R. Lindau, A. Moslang, Annealing behavior of ferritic-martensitic 9\%Cr-ODS-Eurofer steel, Mater. Sci. Eng. A 527, 3602 (2010)
7. P. Moayeart, Investigation of the martensitic transformation using dilatometry, CEA Report, DEN/DANS/DMN/ SRMA/LA2M, 2013

8. A. Ayad, N. Allain-Bonasso, N. Rouag, F. Wagner, Grain Orientation Spread values in IF steels after plastic deformation and recrystallization, Mater. Sci. Forum 702-703, 269 (2012)

9. M. Praud, F. Mompiou, J. Malaplate, D. Caillard, J. Garnier, A. Steckmeyer, B. Fournier, Study of the deformation mechanism in Fe-14\% Cr ODS alloys, J. Nucl. Mater. 428, $90(2012)$

10. M. Klimiankou, R. Lindau, A. Möslang, Direct correlation between morphology of $(\mathrm{Fe}, \mathrm{Cr}){ }_{23} \mathrm{C}_{6}$ precipitates and impact behavior on ODS steels, J. Nucl. Mater. 367-370, 173 (2007)

11. S. Noh, B.-K. Choi, C.-H. Han, S.H. Kang, J. Jang, Y.-H. Jeong, T.K. Kim, Effects of heat treatments on microstructures and mechanical properties of dual phase ODS steels for high temperature strength, Nucl. Eng. Technol. 45, 821 (2013)

12. S. Ukai, S. Ohtsuka, T. Kaito, H. Sakasegawa, N. Chikata, S. Hayashi, S. Ohnuki, High-temperature strength characterization of advanced 9Cr-ODS ferritic steels, Mat. Sci. Eng. A Struct. 510-511, 115 (2009)

13. R. Miyata, S. Ukai, X. Wu, N. Oono, S. Hayashi, S. Ohtsuka, T. Kaito, Strength correlation with residual ferrite fraction in 9Cr-ODS ferritic steel, J. Nucl. Mater. 442, S138 (2013)

14. M. Yamamoto, S. Ukai, S. Hayashi, T. Kaito, S. Ohtsuka, Formation of residual ferrite in 9Cr-ODS ferritic steels, Mat. Sci. Eng. A 527, 4418 (2010)

15. S. Vincent, J. Ribis, Microstructural and mechanical characterization of CEA ODS steels, Technical report, DEN/DANS/DMN/SRMA/LC2M\&LA2M/NT/2013/ $3393 / \mathrm{A}, 2013$

16. C. Cayron, A. Montani, D. Venet, N. Herve, Y. de Carlan, Microstructural characterization of ODS steels after manufacturing and after creep loading, Technical report DEHT/DL/2013/122, 2013

17. H. Bakker, H.P. Bonzel, C.M. Bruff, "LANDOLTBÖRNSTEIN", Group III: Crystal and solid State Physics, Volume 26, Diffusion in Solid Metals and Alloys (SpringerVerlag, 1990), p. 481

18. C.Y. Kung, J.J. Rayment, An examination of the validity of existing empirical formulae for the calculation of $M_{s}$ temperature, Met. Trans. A 13A, 328 (1982)

19. J.L. Béchade, L. Toualbi, S. Bosonnet, Macroscopic and microscopic determination of residual stresses in thin Oxides Dispersion Strengthened steel tubes, Mater. Sci. Forum 768769, 296 (2014)

20. L. Toualbi, Improvement of the manufacturing route of ODS steels cladding tubes, translated from "Optimisation de la gamme de fabrication de tubes en aciers renforcés par dispersion nanométriques d'oxydes (ODS)", $\mathrm{PhD}$ thesis, CEMEF-Mines ParisTech, 2012

Cite this article as: Benjamin Hary, Thomas Guilbert, Pierre Wident, Thierry Baudin, Roland Logé, Yann de Carlan, Investigation of the relationships between mechanical properties and microstructure in a Fe-9\% Cr ODS steel, EPJ Nuclear Sci. Technol. 2, 7 (2016) 